stock notions of how the monsoons are caused in India are so prevalent. The explanations of many of the text-books are in fact a libel on the intelligence of both teacher and pupil.

It is usually said that the air is heated over the land expands, and rises (presumably in a courant ascendant). The air from the sea then rashe; in to supply the tendency to vacurn, and this constitutes the monsoon.

The true state of the case is, however, quite different. The way in which the air is removed from North India is not by ascending, but by lateral currents which constitute the "hot winds." The vertical expansion by which a larger portion of the whole atmosphere is lifted above the level of the hill-stations would indeed rather tend to raise than lower the isobaric planes towards the north, and as no true "courant ascendant" can exist until the air is rendered moist by the monsoon rains, the lateral winds are the only means by which the isobaric planes are caused to slope northwards prior to their arrival.

The annual variation of pressure at the level of Leh, which is II, 538 feet above sea-level, shows us that at a still bigher elevation the phases of annual barometric variation are exactly contrary to those which occur on the plains, the minimum occurring in mid-winter, and the maximum in midsummer.

It is further shown by Prof. Hill that the peculiar double osciliation at the hill-stations, which in correspondence with heir position is intermediate in character to those in the two extreme cases, is due to exactly the same causes as the single oscillation on the plains-a fact which will prove of much utility in further research on this complicated question.

The winds for the most part correspond to the barometric variations. The constant south-westerly direction of the wind at the elevation of the hill-stations is, the result of two independent circumstances, viz. (I) the small depth of the winter (northeast) monsoon, above which the south-west anti-monsoon blows, and (2) the great height to which the summer (south-west) monsoon reaches. Above the latter monsoon it is not known how the wind blows, but in accordance with cyclonic laws it should be north-zwest. Perhaps future research will verify this inference.

The discussion of the humidity observations, leads to results which corroborate some previously obtained from somewhat meagre data by General Strachey. On the assumption that Hann's empirical formula with the value of the constant as given by Hill is correct, viz. -

$$
\log p=\log P-\frac{h}{23058}, 1
$$

it is found that "at an elevation of 23,000 feet, or about the average height of the snowy peaks, the quantity of vapour in the air is only one-tenth of that at sea-level. The extreme dryness of Thibet and Ladakh is thus easily accounted for."

The relative humidity depending on the temperature, obeys quite different laws; and undergoes variations very similar to those in the amount of cloud.

The average height at which cloud would be formed in the rainy season, is calculated by Prof. Hill to be about 4000 feet, and it is interesting to note that this elevation agrees with that of the zone on which the greatest amount of rain falls in the Himalaya, the exact height of which is found to be 4240 feet above sea-level. Above this height the rainfall decreases rapidly owing to the exhaustion of vapour, but in the case of the Himalaya this decrease is rendered more prominent owing to the outer ranges cutting off the supply of vapour to those more in the interior by promoting abnormal precipitation in their own vicinity.

$$
\text { E. Douglas Archibald }
$$

\section{MULTIPLEX CAMERA BACK}

THE great advance in tourist photography by reason of the production of the more sensitive and rapid gelatine dry plates now used in such large numbers has led to continued improvements in the construction of portable photographic apparatus.

Considerable difficulty has always been experienced in carrying a sufficient supply of sensitive plates for a day's tour.

To meet this want not only are large numbers of double backs carried but the changing box has also been devised. The latter consists of a cabinet arranged to carry twelve sensitive plates and a specially constructed dark back for the camera. When a plate is required to be changed, the dark back is attached to the

${ }^{I}$ Where $p P$ are the vapour tensions at the given elevation and sea level respectively, and $h$ is the height in feet. changing cabinet, and by the action of springs and shutters a sensitive plate is transferred from the cabinet to the dark back, which is then removed and exposed in the camera as desired. The changing box is complicated and expensive, besides adding another piece of apparatus to the tourist's luggage. The greatest difficulty, however, arises from the very merits of the gelatine plates themselves.

They are so sencitive that the utmost care is required to keep every trace of light from the plate, and double backs that appear perfect to the eye, yet by the action of the sensitive plates themselves are found to be imperfect. It is obvious that the multiplication of double backs and the shutters forming part of them, adds to the liability of acces: of light and consequent fogging of plates. With the use of a changing box the same trouble is experienced, with occasionally further difficulties, caused by variations in thickness or sizes of sensitive plates, the latter sometimes refusing to pass from the changing box to the back or vice viers $\hat{t}$, very often causing loss of time, temper, and plate as well.

We give illustration and description of an improved apparatus that, by its simplicity of action, appears to obviate the

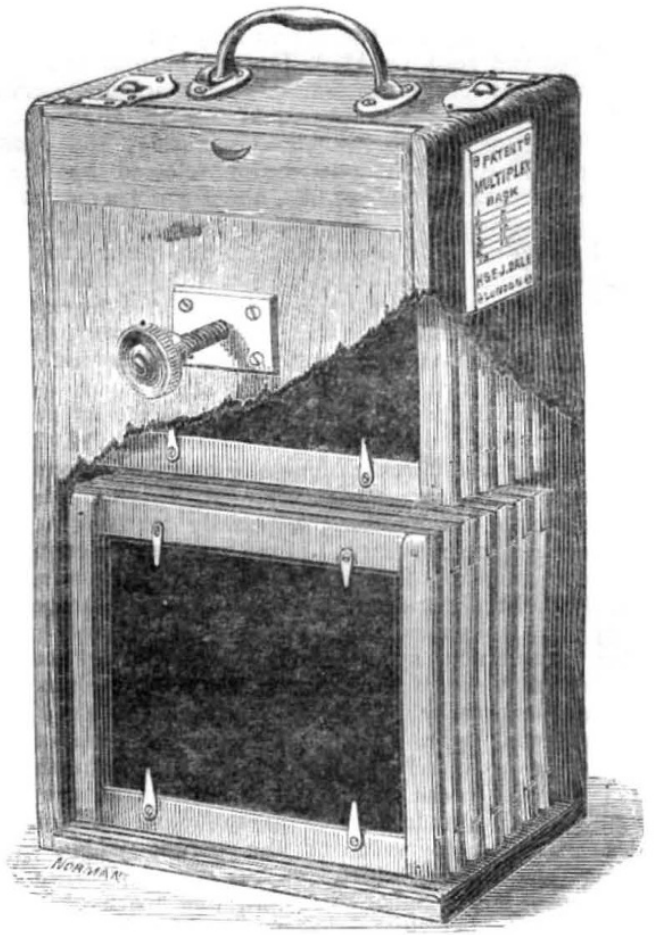

difficulties before mentioned, and to possess merits of its own that will insure the success desired by the inventors. The apparatus combines in one cabinet the dark back and the changing box, and is the invention of Messrs. J. H. Hare and H. J. Dale.

The woodcut (which shows part of the outer cabinet cut away to give a view of the interior construction) will immediately explain its action.

The cabinet or multiplex back is made large enough to contain thirteen plates in two tiers, the lower tier containing seven and the upper tier six plates. The plates are secured in holders or carriers, with a thin metal back to each to prevent the light passing through the plate which may be exposed to those behind it. In the front of the cabinet is the usual sliding shutter, which draws up half way for exposure of the front plate of the lower tier.

At the back of the cabinet is a shutter which can be entirely removed when required to refill the back with plates. In the front shutter a small window of non-actinic glass is provided, throngh which the number of the sensitive plate ready to be exposed can be seen. In the back shutter two quick-running three-thread screws are provided, the lower one to bring the plates of the lower tier up to focus, and the 
upper screw to tighten the upper tier of plates to prevent damage during travelling. The multiplex back fits into the camera in the usual manner. When the plate has been exposed, the shutter is closed, back removed from camera, and both screws at back unscrewed. Then the back is gently turned over; the first half-turn causes the front plate of lower tier (just exposed) to pass into the upper tier, and then the second halfturn causes the back plate of upper tier to pass to the back of lower tier, while the second plate of lower tier has now come to the front, and is ready for exposure.

If any particular plate is required to be exposed, repeat the operation of revolving the box until the number of that particular plate is seen through the window in the shutter. An ivory tablet is provided on the side of the cabinet to register the numbers of the plates as exposed.

\section{SOCIETIES AND ACADEMIES \\ PARIS}

Academy of Sciences, September 3.-M. Blanchard, president, in the chair.-The sitting was chiefly occupied with the reading of the report on the French mission to the Pacific to observe the total eclipse of the sun on May 6, 1883. The report was prepared and read by $M . J$. Janssen, head of the mission, to which, besides M. Trouvelot, of the Meudon Observatory, and M. Pasteur, photographer, were also attached MM. Tacchini, director of the Roman Observatory, and Palisa, of the Vienna Observatory. The station selected was Caroline Island, in $10^{\circ} \mathrm{S}$. and $152^{\circ} 20^{\prime} \mathrm{W}$., about 200 leagues north of Tahiti, a point lying very nearly within the zone of total obscuration. In the report are summed up the results of all the observations, which aimed especially at the solution of certain questions touching the con titution of the sun and the existence of the so-called intra-Mercurial planets. As regards eontact the commencement of total obscuration was determined at $23 \mathrm{~h}$. $3 \mathrm{Im} .5 \mathrm{I} \cdot 8 \mathrm{~s}$. mean time at Caroline Island; end of same $23 \mathrm{~h}$. $37 \mathrm{~m}$. I $5.8 \mathrm{~s}$., leaving a difference of $5 \mathrm{~m}, 24 \cdot 1 \mathrm{~s}$, as the actual duration of totality according to $M$. Trouvelot. M. Tacchini gave $5 \mathrm{~m} .23 \mathrm{~s}$., or a difference of slightly over one second, which was considered as so far satisfactory. M. Tacchini also made some remarkable observations, especially touching a certain analogy between the constitution of the spectrum of certain parts of the corona and that of comets. In his attempt to ascertain whether the light of the corona contains any large proportion of solar ligbt, M. Janssen succeeded beyond his expectations. The complete Frauenhofer spectrum seen by him shows that, apart from what may be due to diffraction, there exists in the corona, and especially in certain parts of it, an enormous mass of reflected light. And as the coronal atmosphere is known to be extremely attenuated, such an abundance of reflected solar light can be explained only by the presence in these regions of cosmic matter in the form of solid corpuscules. The photographs of the corona yielded several interesting phenomena, which are reserved for future study. For the present it will suffice to remark that these photographs show a more extended corona than that obtained from telescopic observation. The phenomenon also appeared limited and fixed during the period of total obscuration. A photometric measure. ment of the luminous intensity of the corona, which M. Janssen bad prepared by means of photography, showed that in Caroline the luminosity of the corona was greater than that of the full moon. This is the first time that a precise calculation has been made of this phenomenon. On May 13 the mission re-embarked on board the Eclaireur, and on the home voyage visited Hawaii during the volcanic disturbances in the crater of Kilauea. M. Janssen took this opportunity of making a spectrum analysis of the flames emitted by the molten lavas, and was able to determine the presence of sodium, hydrogen, and carburetted combinations. - On the antiseptic frigidity of sores, by M. Gosselin.Note by M. J. Delauney on the indications some years ago formulated by him on the probable epochs of great earthquakes. In a note inserted in the Comptes Rendus for November 17, 1879 , the author considered it probable that the influence of Jupiter and Saturn on seismic disturbances is due to the passage of these planets through meteoric bodies situated in the mean longitudes of $135^{\circ}$ and $265^{\circ}$. In the approximate table of future earthquakes accompanying the note, the iyear I883 was not mentioned. But in another note inserted in La Nature for October 23 , 1880 , a fresh calculation of probable epochs of seismic agitation, brought down to the year I920, mention is made of the date $188_{3}-85$, when disturbances might be expecterl owing to the transit of Jupiter through the August meteors. Observations of the new planet (234) made at the Paris Observatory (equatorial of the west tower), by M. C. Bigourdan,-On the affinities of the eocene floras of England and the west of France, by M. L. Crié.-Fresh remarks on the Phylloglossum Drummondii (Kunze), by M. C. Eg. Bertrand. - On a prucess for extracting alcohol by means of lemon juice, by $M$. Levat. On the fermentation of bread-stuffs, by M. G. Chicandard.

\section{VIENA}

Imperial Academy of Sciences, July 12.-D. Stur, on the morphology and systematics of culmian and carbon fauna. -H. Jahn, electrolytic studies (preliminary note).-A. Adamkiewicz, on the theory of brain pressure and on the pathology of brain compression (part ii.) - Th. von Oppolzer, communication on a series of observations (just completed) for the absolute determination of gravity at Vienna.-W. Fossek, on a derivative of isobutyraldehyde analogous to hydrobenzoin.-On the preparation of isobutyraldehyde free from acetone, by the same. II. Molisch, researches on hydrotropism.

July 19.-C. von Ettingshausen, on the Tertiary flora of Japan. -F. Braner, on two parasites of the June beetle ( $R^{2}$ hizostrogus solstitialis): I, Hirmoneura obscura, Mg. ; 2 , Phorostoma lata, Egg.-B, Mandelstamm, studies on innervation and atrophy of the laryngeal muicles.-T. Korteweg, on the question whether the variations in the length and height of the singular periods of frequency of sun-spots were produced by the interference of two periods of unequal but invariable length and height. - V. Hausmanninger, new observations on the impact of cylindrical caout chouc rods. - M. Loewit, on the formation of white and red blood-corpuscles. - L. von Barth and $\mathrm{H}$. Weidel, on the oxidation of morphine. -G. Goldschmidt, on papaverine.-J. Habermann, on some basic sulphates.-On arbutin, by the same.-M. Hoenig and $\mathrm{E}$. Zatzek, on the direct estimation of carbonic acid in presence of sulphides, sulphites, and thiosulphates. - On the action of permanganate of potassium on some sulphur compounds, by the same.-A. Waage, on the action of ammonia on propionaldehyde.-E. Lippmann and F. Fleissner, contribution to a knowledge of azylines.

\section{CONTENTS}

PAGE

Scientific Aspects of the Java Catastrophe . . . 457

Autumn Sanitation . . . . . . . . . . . . 458

Tropical Agriculture. By Prof. W. Fream . . . 459

Our Book Shelf :-

Sachs's "Vorlesungen über Pflanzen-physiologie"

Jackson's "Accented Five-figure Logarithms of Numbers from I to 99999 without Difference". . .

Letters to the Editor:-

The Earthquake of Ischia.-Prof. J. P. O'Reilly . 46r

Mr. Romanes and Modern Philosophy. - Alfred Stapley

Animal Intelligence- $-\mathrm{A}^{\circ} \mathrm{B}$

- $46 \mathrm{I}$

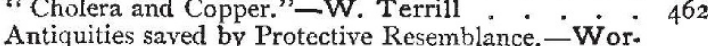
thington G. Smith

Meteor-Thomas H. Potts . : . : . : : 4462

The Meteor of August 19.-C. D. : . : . : : 462

Hermann Mitller . . . . . . . . . . . . 462

Second Note on the Electrical Resistance of the Human Body. By Dr. W. H. Stone . . . . 463

The International Bureau of Weights and Measures (With Ilhistrations).

The Vienna International Electric Exhibition . . 466

The Edinburgh Biological Station . . . . . . 467

Notes . . . . . . . . . . . . . . . 468

Our Astronomical Column :-

The Total Solar Eclipse of May 6 . . . . . . 47I

A New Comet . . . . . . . . . . . : 47x

The German Survey of the Northern Heavens. By

Frof. William A. Rogers

Indian Meteorology, III. By E. Douglas Archibald 471

Multiplex Camera Back (With Illustration) . . . . 479

Societies and Academies . . . . . . . . . 480 